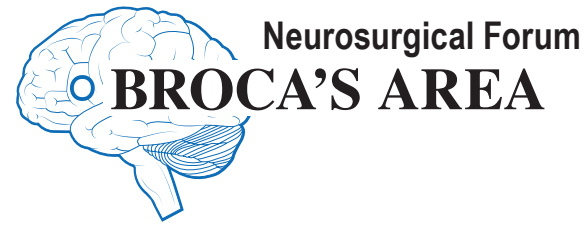

\section{Women in neurosurgery: inequality redux}

\author{
Aviva Abosch, MD, PhD, ${ }^{1}$ and James T. Rutka, MD, PhD ${ }^{2}$ \\ 'Department of Neurosurgery, University of Colorado-Anschutz Medical \\ Campus, Aurora, Colorado \\ ${ }^{2}$ Editor-in-Chief, Journal of Neurosurgery Publishing Group, \\ Charlottesville, Virginia
}

I N April 2018, Dr. Shelly Timmons assumed the mantle of President of the American Association of Neurological Surgeons (AANS) (Fig. 1). It is worth taking this moment to reflect on the fact that this is the first time in its 86-year history that the AANS is being led by a female neurosurgeon. Trumpeting this accomplishment nationally provides an extraordinary opportunity to engage the attention and imagination of female students, trainees, and neurosurgeons around the US and the world, and to send a clear message to our neurosurgical and non-neurosurgical colleagues, including those who populate key roles on university search committees and in hospital administration, that women are valued in neurosurgery.

This singular accomplishment by Dr. Timmons allows us to reflect not only on the status of women in neurosurgery but also on the status of women in the workforce in general, a topic that has been informed by several recent publications and op-eds on gender disparity in society. Across all professions, disciplines, and career paths, women are underrepresented at virtually every level in corporate America. ${ }^{7}$ This inequality has been shown to start as early as the time of first promotion, and it becomes progressively more manifest at subsequent levels of career advancement. Women are far less represented in higher levels of corporate management. When compared with their male counterparts, women far less frequently occupy "C-suite" positions (i.e., chief executive officers, chief operating officers, and chief financial officers). Worse, a gender pay gap exists across nearly all disciplines, with women receiving $20 \%$ less compensation than men in the same positions or for performing the same amount of work as men (https://leanin.org/equal-pay-data-aboutthe-gender-pay-gap). These facts, coupled with recent attention focused on the \#MeToo social media movement against sexual harassment and assault, especially in the workplace, make this an opportune time to review ways in which organized neurosurgery has responded to issues of gender disparity and diversity, and to offer possible solutions to improve career opportunities for women in neurosurgery in the future.

A dozen years ago, a light was shone on the issue of gender inequality in neurosurgery through the publication of two reports. ${ }^{14,16}$ In one, Venes drew attention to the facts, still true today, that female neurosurgeons are paid less than male neurosurgeons when working in similar jobs, and that adequate mentorship of female neurosurgeons is lacking. ${ }^{14}$ Venes argued that women may be held to a higher standard than men in becoming leaders in the field of neurosurgery, hence the conspicuous absence of female neurosurgeon leaders at the state or national level. One solution to this inequity was to encourage more female neurosurgeons to complete nationwide leadership programs, such as the Hedwig van Ameringen Executive Leadership in Academic Medicine (ELAM) Program for Women.

In the other report in 2006, Woodrow et al. performed a critical analysis of the neurosurgical workforce in North America, concentrating on gender issues.${ }^{16}$ At that time, an estimated $13 \%$ of practicing surgeons and $6 \%$ of neurosurgeons in North America were women, with the number of female neurosurgical residents totaling approximately $12 \%$. Numerous factors were identified that were causally related to this gender inequality in neurosurgery, including the inflexible work environment of neurosurgical practices, unconscious bias and harassment, increased home and family responsibilities, and the lack of adequate mentoring and role models. As potential solutions, these authors suggested that a concerted effort to attract more female neurosurgeons in the early years of medical school, job sharing paradigms, consistent parental leave policies, on-site day care facilities, and meaningful mentorship programs for women in neurosurgery would all serve to reduce gender inequality in neurosurgery. ${ }^{16}$ 


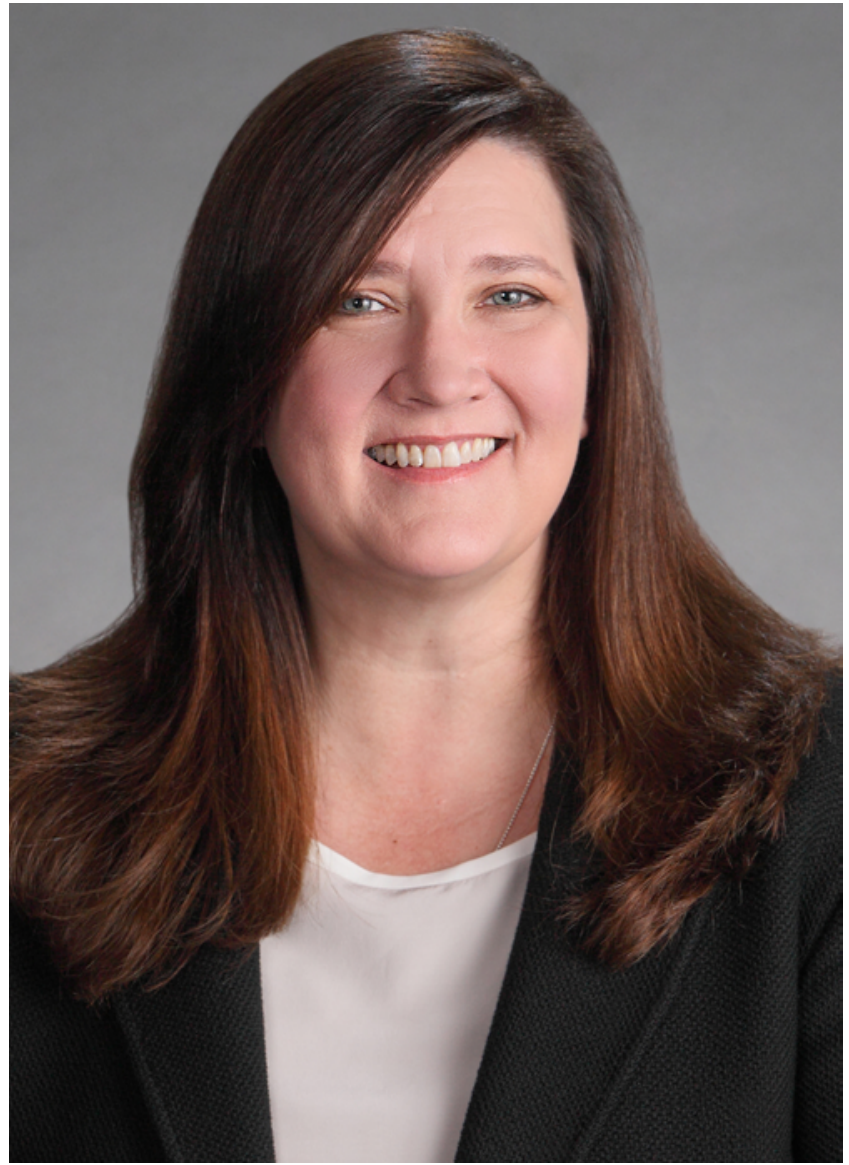

FIG. 1. Dr. Shelly Timmons, first female neurosurgeon President of the AANS. Official AANS Presidential photograph, copyrighted by the AANS. Figure is available in color online only.

Following the publication of these two papers, the AANS commissioned a white paper from the Women in Neurosurgery (WINS) Committee of the AANS on the topic of recruitment and retention of women in neurosurgery. Benzil et al. published their findings in this Journal in 2008 , noting that at that time, there had never been a female President or Executive Committee officer of the AANS; there had never been a woman appointed to the Board of Directors of the American Board of Neurological Surgery (ABNS); there were only two female members of the Society of Neurological Surgeons (SNS); there was only one female neurosurgery departmental chair (at the University of Michigan since 2005); and there were four neurosurgery training programs in the US that had never trained a female resident. ${ }^{3}$ The white paper underscored the reality that women were rarely groomed to become leaders within or chairs of their neurosurgical departments and were concerned about gender inequality in salaries, academic promotion, and achieving leadership positions. As potential solutions to the gender imbalance in neurosurgery, Benzil and colleagues called for a zero tolerance policy on sexual harassment, the creation of workshops on negotiating skills for academic or hospital contracts, and a redesign of the medical student curriculum to more vigorously attract prospective female neurosurgical trainees and to promulgate the importance of diversity at all levels of neurosurgery training, practice, and leadership.

In response to the publication of the white paper in the pages of this Journal, Dr. James Bean penned an editorial about women in neurosurgery. In his editorial, Dr. Bean reflected on the moral and political principles of equality on which our nation was founded, and on how progress toward realizing this goal of equality had been "halting and uneven and marred by...hope disappointed, and promise denied." 2 The white paper charged organized neurosurgery with a call-to-action to attain a $20 \%$ female complement within residency training programs by 2020 and a $20 \%$ female faculty complement by $2020 .{ }^{3}$

A glimmer of hope was found with the analysis of neurosurgery enrollment and attrition within the 2000-2009 female resident cohort that matched to neurosurgical training programs when compared to the prior epoch of 1990-1999.11 Over these two epochs, attrition of female neurosurgery residents had declined from $25 \%$ to $17 \%$. The success in attracting and retaining female neurosurgical trainees was thought to be directly attributable to efforts by WINS at codifying its mentorship program and providing more than 250 pairings since 2010 between female or male mentors and aspiring female neurosurgeons.

A decade has now passed since the publication of the WINS white paper in the Journal. How does the scorecard for organized neurosurgery look? After analyzing the results of 18 annual neurosurgery residency match cycles in the US, Durham and colleagues showed that United States Medical Licensing Examination (USMLE) Step 1 score was the greatest predictor of successfully matching in a neurosurgery residency program, with the national ranking of an applicant's medical school also significantly associated with match outcome. ${ }^{4}$ Interestingly, after adjusting for applicant USMLE Step 1 scores and medical school national rank, female neurosurgery residency applicants still "appeared to be less likely to match into neurosurgery [training programs] than male applicants."

Furthermore, with women still representing only $6 \%$ of ABNS-certified practicing neurosurgeons, $8 \%$ of all practicing neurosurgeons in the US, and fewer than $20 \%$ of the applicants to neurosurgery training programs, the gender trends for neurosurgery are at odds with trends for medical school attendees. In 2017, for the first time, the number of women enrolling in US medical schools exceeded the number of men, with women now representing $51 \%$ of matriculating medical students. ${ }^{8}$ So why, then, does gender parity in neurosurgery seem so remote a goal?

The rigors of a neurosurgical profession certainly pose a deterrent to some medical students-of either genderas they consider career paths, and should raise questions about work-life balance for anyone contemplating this profession, as articulated in a recent perspective in The Lancet by a first year neurosurgery resident. ${ }^{17}$ However, examples exist of demanding professions in which women have made far greater inroads with respect to leadership positions than in neurosurgery. For instance, in 2017, women held $20.2 \%$ of board seats, and accounted for $5.4 \%$ chief executive officers of Fortune 500 companies and 19.4\% of the US House of Representatives. ${ }^{5}$ Women remain underrepresented in academic medicine, as a whole, however, 
representing only $19 \%$ of total medical center departmental chairs in 2015. ${ }^{8}$ However, this figure of $19 \%$ stands in stark contrast to the fact that there have only ever been two women appointed as chairs of neurosurgery departments at US academic medical centers with residency training programs (University of Michigan and UCLA). Given that leadership positions beget higher leadership positionsfor example, deans of medical centers are selected from the ranks of department chairs - it is not surprising that there is a pipeline effect, in that the existence of fewer female tenured professors leads to fewer female department chairs, which in turn leads to fewer female deans.

Let's return to the question of why women constitute only $6 \%$ of ABNS-certified practicing neurosurgeons but now $51 \%$ of graduating medical students. Perhaps the underrepresentation of women in neurosurgery is more a consequence of discrepancies in opportunities, mentoring, or conscious or unconscious bias on the part of residents and faculty encountered during the course of medical school or even during undergraduate education, than of female medical students opting out of considering neurosurgery as a career choice. The evidence supporting the presence of such implicit gender bias in the fields of Science, Technology, Engineering, Mathematics, and Medicine (STEMM) was eloquently described in a recent editorial by Welle and Asplund in Neuron. ${ }^{15}$ The argument that these authors make against bias derives from the fact that limiting diversity limits science, productivity, and innovation. As yet, unfortunately, no study has investigated the presence or extent of implicit bias within neurosurgery, or the possibility of resultant limitations placed on our field. In another recent article describing the gender gap in science, Holman and colleagues examined the gender of more than 36 million authors in more than 6000 journals worldwide. They showed that the fields of surgery, computer science, physics, and math continue to demonstrate a wide gender gap favoring men, especially for authorship positions and high-impact journals. ${ }^{6}$ Importantly, in their analysis, the Journal of Neurosurgery was identified as one of the journals that needs corrective measures to address the gender gap in authorship, along with Lancet, JAMA, NEJM, and Anesthesiology, to name a few. ${ }^{6}$

Adding to discrepancies in opportunity, there is a clear dearth of female leaders within neurosurgery. Some female medical students considering a career in neurosurgery may be understandably discouraged to find no female neurosurgeon on faculty at their institution as well as very few female leaders evident on the national scene. In a recent study by Renfrow et al., there were 16 female full professors of neurosurgery, constituting only $4 \%$ of the total number of full professors of neurosurgery in the US. Only the field of orthopedics demonstrates a lower percentage $(1 \%)$ of female full professors, whereas some specialties, such as pediatrics and family medicine, can claim a much higher percentage (19\% and $18 \%$, respectively). ${ }^{12}$ It is worth noting here that this year, a Stanford University neurosurgeon, Dr. Odette Harris, became only the second African-American female tenured neurosurgery professor in US history, after Dr. Alexa Canady at Wayne State University. ${ }^{13}$ While the focus of this article is on gender diversity in neurosurgery, we emphasize that diversity of all types should be embraced in neurosurgery for the continued advancement and vigor of our field.

Pregnancy and parental leave are among the most important issues to address for female neurosurgical trainees and practicing neurosurgeons, and doubtless contribute to smaller numbers of female residency applicants and higher attrition rates of female trainees and neurosurgeons. In a recent survey analysis of 347 female surgeons, $63 \%$ responded that an unmodified surgical residency program during pregnancy was perceived as unhealthy for either the female surgical trainee or the unborn child. ${ }^{10}$ Perhaps of most concern, approximately $40 \%$ of female surgeons considered leaving surgical residency, and 30\% would discourage female medical students from a surgical career because of the challenges of balancing pregnancy and motherhood with surgical training. ${ }^{10}$ In its recent Women in Surgery Taskforce Report, the Royal College of Surgeons of Ireland (RCSI) stressed the need to build a culture that supports female surgical trainees, including the requirement to provide meaningful options for parental leave, and to consider the special needs of trainees who are parents. ${ }^{9}$ In addition, the report states that support should be provided by hospitals and institutions for extended child care hours. These issues were also discussed in a recent commentary by Acai et al., in which it was suggested that we should be shifting our focus to developing more equitable solutions for caregiving to improve the gender gap in surgery and to provide for a healthier and more just society. ${ }^{1}$

Even with the appointment of Dr. Timmons as AANS President, there is of course still much more ground for us to cover. Organized neurosurgery should develop a comprehensive plan to advance and support the careers of women in neurosurgery. As a consequence of underrepresentation, women cannot effect the changes necessary in neurosurgery by themselves. Men in neurosurgery should work with groups such as WINS to create a blueprint for change (Fig. 2). Together, we must continue to systematically track statistics on gender in our profession; we must increase the representation of women at all levels of neurosurgery training, professional development, and organized neurosurgery leadership; we must ensure that our national associations, congresses, and societies work toward gender parity on all committees; we must reform the peer review process in our journals and academic publishing to reach parity for women and men on scientific publications; we must encourage residency training programs that have never matched a female resident and departments that have never hired a female faculty member to vigorously pursue diversity in their hiring practices; we must prioritize the invitation of female neurosurgeons for keynote and invited lectureships in our departments and at national meetings; we must advocate strongly for standardized institutional and state support for meaningful, paid parental leave times and adjustments in surgical training to protect the health of pregnant surgical trainees and their unborn children; we must stay vigilant so as to avoid gender discrimination in the hiring of new faculty and in the publication process of our journals; we must completely eliminate harassment in the workplace, which remains all too prevalent, as highlighted by the \#MeToo 
INEOUALITY

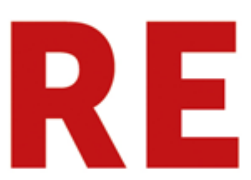

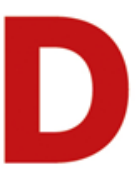

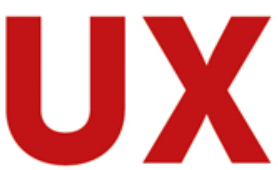

The barriers (for women) may neither be obvious nor even acknowledged, but they exist."

DR. JAMES BEAN, 2008

Editorial about women in neurosurgery

\section{WHAT'S THE ISSUE?}

- Unconscious bias

- Harassment

- Increased home and family responsibilities

- Lack of mentoring and role models

- Inequality in salaries and academic promotion

\section{TRICKLE-DOWN ACADEMICS \\ WOMEN MAKE UP:}

$51 \%$ of matriculating medical students

$<20 \%$ of applicants to neurosurgery training programs.

$8 \%$ of practicing neurosurgeons in the US

$6 \%$ of ABNS-certified practicing neurosurgeons

\section{FEMALE TRAINEES IN NEUROSURGICAL PROGRAMS}

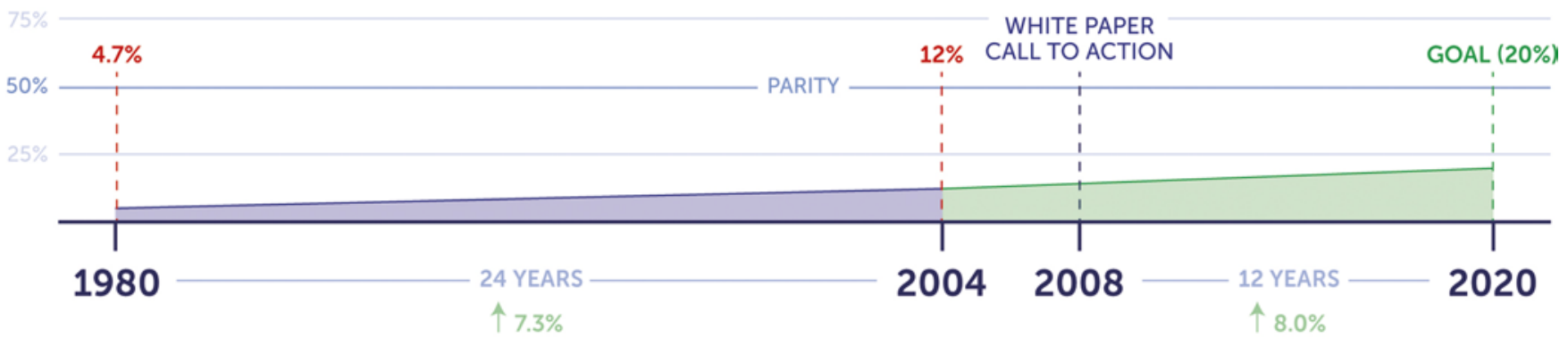

NEUROSURGERY

\section{RESIDENCY MATCHING}

Greatest predictors of successfully matching into a neurosurgery residency program in the US:

(1) USMLE STEP 1 SCORE

(2) APPLICANT MEDICAL SCHOOL NATIONAL RANKING

Adjusting for both, female neurosurgery residency applicants still "appeared to be less likely to match into neurosurgery" than male applicants.

\section{WHAT'S THE SOLUTION?}

- Job sharing paradigms

- Consistent and meaningful options for parental leave

- On-site day care facilities, extended child care hours

- Meaningful mentorship programs

- Pursue diversity in hiring practices

- Prioritize the invitation of female neurosurgeons for keynote and invited lectureships

- Equal and fair remuneration for equal work

- Systematically track statistics on gender in neurosurgery

- Eliminate harrassment in the workplace with zero tolerance policies

FIG. 2. Infographic depicting numbers of female neurosurgeons in neurosurgical societies, associations, and university institutions. Possible solutions to the imbalance in gender diversity in neurosurgery are listed. Figure is available in color online only. 
social media movement; and we must ensure that female neurosurgeons who are working in the same positions and performing the same work as their male counterparts receive equal and fair remuneration, hearkening back to the point made by Venes. ${ }^{14}$

So, at the 10-year anniversary of the publication of the WINS white paper, it is worth reflecting on the following: The dramatic rise in female medical school graduates over the last 25 years to $51 \%$ has been accompanied by a much more tepid rise in female neurosurgery residents and really no significant rise in female neurosurgeons in the US. Other traditionally male-dominated professions have fared much better in comparison. Implicit gender bias in neurosurgery, as in the rest of the STEMM professions, is likely a major factor; data support the notion that both men and women are guilty of this implicit bias. Diversity-gender and otherwise-is both morally right and necessary for our field to advance and to remain vital. We, collectively, need to work to eliminate this bias on Search Committees, Study Sections, Editorial Boards, Society Leadership and Executive Committees, mentoring efforts, invited lectureships, and Residency Selection Committees. The appointment of Shelly Timmons, MD, to President of AANS is a golden opportunity to reassess our directionality and refocus our efforts toward this goal.

We owe to our daughters - and to the health of our profession-the promise that we will improve things for the next generation. Our hope is that, in another 10 years, an editorial revisiting the same themes on gender inequality in neurosurgery, will not be required. We are confident that if we work together with our national organizations in neurosurgery, our accrediting medical bodies, the national and state legislatures, and our universities and hospitals, we can ultimately eliminate bias in neurosurgery and establish a culture that fosters and acknowledges the success of women in neurosurgery at all levels of our specialty.

\section{Acknowledgments}

We thank Drs. Deborah Benzil, Ann Parr, and James Bean for their many helpful suggestions in the writing of this article.

\section{References}

1. Acai A, Steyn C, Reid SE, Sonnadara RR: A solution to gender inequity in surgery? Better caregiving policies. Can J Surg 61:6-7, 2018

2. Bean J: Women in neurosurgery. J Neurosurg 109:377, 2008

3. Benzil DL, Abosch A, Germano I, Gilmer H, Maraire JN, Muraszko K, et al: The future of neurosurgery: a white paper on the recruitment and retention of women in neurosurgery. $\mathbf{J}$ Neurosurg 109:378-386, 2008
4. Durham SR, Donaldson K, Grady MS, Benzil DL: Analysis of the 1990-2007 neurosurgery residency match: does applicant gender affect neurosurgery match outcome? J Neurosurg [in press], 2018

5. Fortune Editors: These are the women CEOs leading Fortune 500 companies. Fortune. June 7, 2017 (http://fortune. com/2017/06/07/fortune-500-women-ceos/) [Accessed May $18,2018]$

6. Holman L, Stuart-Fox D, Hauser CE: The gender gap in science: how long until women are equally represented? PLOS Biol 16:e2004956, 2018

7. Krivkovich A, Robinson K, Starikova I, Valentino R, Yee L: Women in the workplace 2017. McKinsey. October 2017. (https://www.mckinsey.com/featured-insights/gender-equality/women-in-the-workplace-2017) [Accessed May 18, 2018]

8. Lautenberger DM, Dandar VM, Raezer CL, Sloane RA: The State of Women in Academic Medicine: The Pipeline and Pathways to Leadership, 2015-2016. Washington, DC: Association of American Medical Colleges, 2017

9. McNamara D: Progress: Promoting Gender Equality in Surgery. Report of the Gender Diversity Short Life Working Group. Dublin: Royal College of Surgeons of Ireland, 2017 (http://rcsi.ie/files/newsevents/ docs/20170707051740_Gender-Diversity-in-Surgery-Re.pdf) [Accessed May 18, 2018]

10. Rangel EL, Smink DS, Castillo-Angeles M, Kwakye G, Changala M, Haider AH, et al: Pregnancy and motherhood during surgical training. JAMA Surg [epub ahead of print], 2018

11. Renfrow JJ, Rodriguez A, Liu A, Pilitsis JG, Samadani U, Ganju A, et al: Positive trends in neurosurgery enrollment and attrition: analysis of the 2000-2009 female neurosurgery resident cohort. J Neurosurg 124:834-839, 2016

12. Renfrow JJ, Rodriguez A, Wilson TA, Germano IM, Abosch A, Wolfe SQ: Tracking career paths of women in neurosurgery. Neurosurgery 82:576-582, 2018

13. Santos M: Odette Harris named America's second female African-American neurosurgery professor at Stanford. Stanford Daily. March 9, 2018 (https://www.stanforddaily. com/2018/03/09/odette-harris-named-americas-first-femaleafrican-american-neurosurgery-professor-at-stanford/) [Accessed May 18, 2018]

14. Venes J: Women in neurological surgery. J Neurosurg (4 Suppl Pediatrics) 104:227-232, 2006

15. Welle C, Asplund M: NeuroView. Women in science. Neuron [in press], 2018

16. Woodrow SJ, Gilmer-Hill H, Rutka JT: The neurosurgical workforce in North America: a critical review of gender issues. Neurosurgery 59:749-758, 2006

17. Yan H: A day in the life of a surgical intern: women in surgery. Lancet 391:830-831, 2018

\section{Disclosures}

The authors report no conflict of interest. 